\title{
LA FINANCIARIZACIÓN ESTRUCTURAL DEL CAPITALISMO, UNA APROXIMACIÓN A ANÍBAL QUIJANO
}

\author{
THE STRUCTURAL FINANCIALIZATION OF CAPITALISM, AN \\ APPROACH TO ANÍBAL QUIJANO \\ (iD) Carlos Escudero Núñez ${ }^{*}$ \\ carlos.escudero@up.ac.pa \\ ${ }^{1}$ Universidad de Panamá, Panamá
}

*Correspondencia: Carlos Escudero Núñez. Email: carlos.escudero@up.ac.pa

Recibido: 15.07.21 | Aprobado: 14.08.21

\section{RESUMEN}

En las últimas décadas el capital global dejó de ser un sistema soportado por la producción de bienes materiales y el intercambio comercial para convertirse en un sistema especulativo sostenido por la financiarización, en donde la confianza se transformó en un activo transable y comercializable. Desde mediados del siglo XIX e inicios del XX sucedieron diversas crisis del capital financiero que demostró su inestabilidad y volatibilidad arrastrando a su paso economías siendo las más afectadas las que se encuentran en el sur global o los que históricamente se han encontrado bajo el control/dominio del poder y el capital hegemónico colonial. Aníbal Quijano visibilizó estos cambios los cuales se interrelacionan con el racismo, la dependencia al poder simbólico y cultural, que continúa recreando el pensamiento del sujeto social colonizado, además, de descifrar el mensaje epistémico para concretar la emancipación y la independencia estructural que necesita Latinoamérica.

Palabras clave: Financiarización, neoliberalismo, colonialidad del poder, aníbal quijano.

\section{ABSTRACT}

In recent decades, global capital stopped being a system supported by the production of material goods and commercial exchange to become a speculative system supported by financialization, where trust was transformed into a tradable and marketable asset. From the mid-nineteenth century and the beginning of the twentieth century, various crises of financial capital occurred that demonstrated its instability and volatility, dragging economies where the most affected would be those in the global south or those that have historically been under control / dominance of power and colonial hegemonic capital. Aníbal Quijano made these changes visible, which are interrelated with racism, dependence on symbolic and cultural power, which continues to recreate the thought of the colonized social subject, in addition to deciphering the epistemic message to realize the emancipation and structural independence that Latin America needs.

Keywords: Financialization, neoliberalism, coloniality of power, aníbal quijano. 


\section{INTRODUCCIÓN}

Para comprender el pensamiento de Aníbal Quijano hay que adentrarnos por nuestra realidad geográfico histórico cultural, la cual enfrenta una serie de procesos de una dependencia colonial a raíz de las transformaciones violentas e impositivas de los intereses económicos globales de los últimos siglos. En la actualidad estos instrumentos han adoptado nuevas formas de explotación, saqueo y expolio como son; la financiarización y la tercerización de un capitalismo posindustrializado en una región como Latinoamérica que por décadas ha carecido de un proyecto de desarrollo nacional y en donde las burguesías industrializadas y terratenientes han desflorado el campo de una posible bonanza económica y social.

La tarea de entender estos procesos lleva años funcionando en el sistema global y se debe partir por las diferentes acepciones que existen para ir identificándolos. Conceptos como colonialidad, identidad, cultura y dominación son acepciones que pensadores como Aníbal Quijano desarrollaron de forma extremadamente lúcida y que nos ayudan a entender cómo el proceso de colonialidad se manifiesta y desarrolla hoy, rezagos de décadas de una historia violenta y cargada de simbolismos que no han desaparecido, sino al contrario, se han vuelto más encostrados en el lenguaje, la siquis y en especial se traducen en la materialidad estructural del hombre y la mujer latinoamericano/a.

Uno de los puntos para entender esta problematización es conocer el circuito hegemónico que implica la financiarización hoy en día. Pareciera algo que no estaría vinculado con el pensamiento de colonización, sin embargo, veremos que tiene mucho que ver con los nuevos ciclos que estarían reconfigurándose con el capital y el sistemamundo. Capital de inmensas capacidades que circula globalmente y que tiene la capacidad de gobernar en las sombras, modificar países, colocar cantidades inmensas de dinero en algunos puntos o desabastecer otros, así como crear crisis y a la vez "solucionarlas".

Más allá de las crecientes deudas externas, los fondos buitres, la inflación o deflación, así como las crisis que se han generado en el mundo en especial en América Latina, el capital industrial se encontraba mermado por parte del abandono y la desidia de los empresarios regionales que en su mayoría se habían volcado hacia nuevas formas de inversión, por el interés de mayores dividendos, flujos constante de capital, activos negociables, bonos soberanos, intereses a largo plazo y ganancias sostenidas en especulación que ofrecían y ofrecen la banca de inversión, los activos digitales y la finanzas. En los últimos años, la región demostró ser un escenario de constante pugnas por el poder comercial y financiero, alianzas entre banqueros, fondos de pensiones, consolidaciones, capital hegemónico que aparece y desaparece en las sombras al calor de las concordancias y las políticas de cada país, así como de las laxas legislaciones e intereses.

Para las personas no legos en los términos financieros sugerimos iniciar con entender, ¿qué es financiarización?, para luego analizar cómo se relación los conceptos de financiarización con la teoría de la colonialidad del poder, y, por último, la contribución de Aníbal Quijano en el entendimiento de estos cambios cada vez más acelerados en Latinoamérica y el sur global. 


\section{UN MUNDO FINANCIADO Y UN SISTEMA FINANCIADOR}

El mundo cambió de forma abrupta producto de las crisis financieras surgidas a partir del 2007 en los Estados Unidos. La historia conocida hasta la década de los 90 se ha habían vuelto un mar de incertidumbres económicas y financieras que vino a demostrarnos coletazos de un sistema económico que se resiste a la transición, que con el tiempo mutó y se acogió a los cambios tecnológicos desarrollándose más allá de la materialidad estructural, el mundo económico ya no necesitaba un "cuerpo" se envolvió en una esfera de especulación y dominio del conocimiento, la red y el hipervínculo de las relaciones del poder financiero que de forma cifrada y algorítmica dice, que ya no es el "color" ni la "raza" sino el manejo del activo, el pasivo y el patrimonio relacionándose con los cambios migratorios, las movilizaciones sociales, el proceso de desindustrialización, la desarticulación de los sectores organizativos, el desmantelamiento de las industrias productivas, así como el incremento del desempleo, la pobreza, la marginalidad y el trabajo precario con sus secuelas de flexibilización.

Las dependencias que sufrían muchos países del sur global fueron ampliamente explicadas con los teóricos de la dependencia en las décadas de los 60,70 y 80, hoy en día siguen tan vigentes que nunca, para articularse con la colonialidad, aunque nunca estuvieron separadas si mantenían por espacios una dimensión y objeto de estudio definido.

Para entender la colonialidad del poder hay que entender la dependencia de nuestras naciones, y viceversa, puesto que siglos de dominación colonial han creado rezagos y simbolismos no solo en el imaginario colectivo sino también en el plano material que acarrean en desinterés de las clases dominantes por proyectos de larga duración como proyectos de un Estado-Nación o proyectos de unidad latinoamericana. Debemos tener en cuenta que el dominio colonial sigue siendo vigente y tan latente que crea formas "maquilladas" a simple vista, como indicará la obra "Piel negra, mascaras blancas" de Frantz Fanon.

La dependencia financiera y monetaria, la deuda externa, el incremento de las sanciones a países endeudados, ya sea por la búsqueda de su libertad (Haitî), o por el impago de los intereses de la deuda externa, la acumulación financiera, el servicio fiscal global, las agencias de calificación, así como las listas "negras", "grises" entre otros colores, nos dicen que la colonialidad no ha desaparecido, y la dependencia mucho menos, sigue estando vigente, como si los países colonizadores mantuvieran todavía un feudo y ese feudo fuera el sur global.

A partir de 1950, los países en el mundo comenzaron a sentar las bases de propuestas financieras que buscaran un nuevo pacto global para cimentar las bases para un solo patrón de intercambio que facilitará el comercio mundial. La Segunda Guerra Mundial fue solo un parteaguas en donde este proyecto se "impulsó", mientras el mundo se estaba destruyendo se establecieron las pautas y lineamientos que deberían seguir los países más industrializados. Con el acuerdo de Bretton Woods de 1946, nacerían las propuestas de dominación y posicionamiento del dólar a nivel imperial, así como el Fondo Monetario Internacional, el Banco Mundial, la Organización para la Cooperación y el Desarrollo, el Consejo General de Aranceles Aduaneros y Comercio, entre otras 
organizaciones de interés monetario. En principio el acuerdo era crear una política librecambista y eliminar todo rastro de un Estado proteccionista, recordemos que años previos a la contienda, las críticas a los modelos Keynesianos eran constantes especialmente de países como los Estados Unidos.

Para mediados del siglo XX, en América Latina y de la mano de Raúl Prébisch, Celso Furtado, entre otros, se da comienzos al programa de la Comisión Economía para América Latina, conocida como la CEPAL como el eje de partida de múltiples procesos en la ingeniera económica en la región.

Una vez dado el fracaso del sistema monetario de Bretton Woods y sumadas la crisis del petróleo en los 70, se impusieron nuevas recetas globales, rediseñando el camino de la financiarización como objetivo. Pero ¿qué es la financiarización? (Medialdea y Sanabria, 2013) la define como "el ascenso de la importancia del capital financiero dentro del funcionamiento económico" por otro lado, (Dutta y Thomson, 2018), la definen como "el papel o rol que han adquirido los procesos de intermediarios financieros en las economías nacionales e internacionales a nivel global" entendiéndose esto como una transformación radical de economías enteras, desde hogares, empresas hasta el funcionamiento de los sistemas monetarios y los mercados de productos básicos a nivel global. Existe un mundo que está supeditado a un sistema global en red, el cual se hace dependiente uno del otro, significando que esta dependencia sea en estricto reglamentaria.

Múltiples investigaciones a nivel global han presentado cómo la financiarización ha aumentado la desigualdad, ralentizado la inversión en la producción "real", incrementado la presión sobre las personas y los hogares endeudados y dado lugar a una merma de la responsabilidad democrática en el mundo, sin dejar de mencionar las enormes ganancias obtenidas en los últimos años por el 1\% del poder global. En el grafico $\mathrm{N}^{\circ} 1$ se puede ver cómo está distribuido la rentabilidad de las empresas.

\section{Gráfico $\mathbf{N}^{\circ} 1$}

Tasa de rentabilidad de las empresas privadas financieras y no financieras en EE.UU.: 19792010

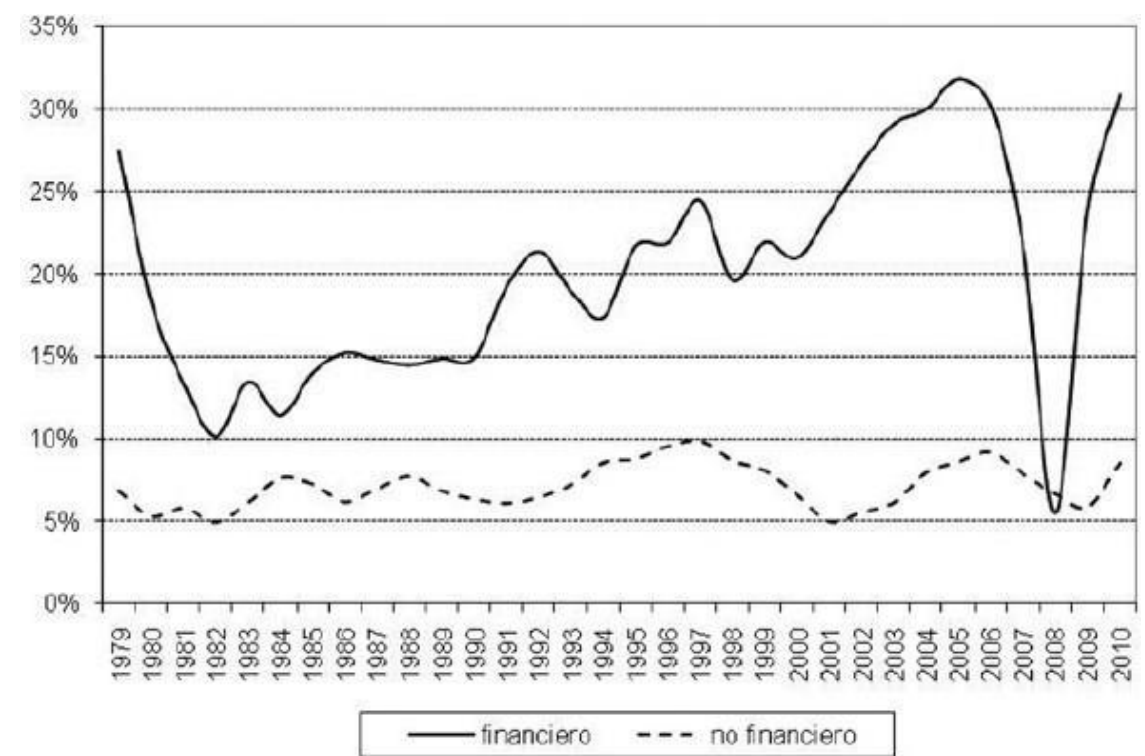

Fuente: (Medialdea y Sanabria, 2013). La financiarización de la economía mundial, datos obtenidos por los autores, del Bureu of Economic Analysis (BEA), Department of Commerce, de EE. UU. 
Las ganancias que han obtenido las organizaciones financieras en los últimos años han sido desorbitantes, por encima de las organizaciones no financieras, dígase sectores de producción industrial, producción de utilidades, mercancías entre otros. El incremento y el dominio que existe hoy en día de la financiarización llega a estados inimaginables a nivel global, podríamos estar pensando en un nuevo metabolismo del capital "apetitos predatorios del capital financiero" (Quijano, 2014).

Las divisas dejan de ser primordialmente un instrumento al servicio de las transacciones económicas internacionales para convertirse en un activo financiero con dinámica propia. A este asunto lo expresan (Medialdea y Sanabria, 2013: 200) que "la aplicación de las medidas neoliberales de las últimas décadas vendría a ser la clave en la génesis de la financiarización de las economías.

En el gráfico N. 2, se muestra cómo el porcentaje de los activos financieros en los últimos años ha ido en un incremento desorbitante por encima del PIB mundial. Teniendo en cuenta que para el 2013, el incremento porcentual mundial fue de $329 \%$ unos $\$ 242$ Billones de dólares, esto nos demuestra el tipo de poder que tiene el sistema financiero global frente a lo que podríamos llamar la producción interna o media comercial de cada país, los cuales cada vez se encuentran más dependientes del "fascismo financiero" (Ríos, 2011: 391).

\section{Gráfico $\mathbf{N}^{\circ} 2$}

Activos financieros a escala mundial

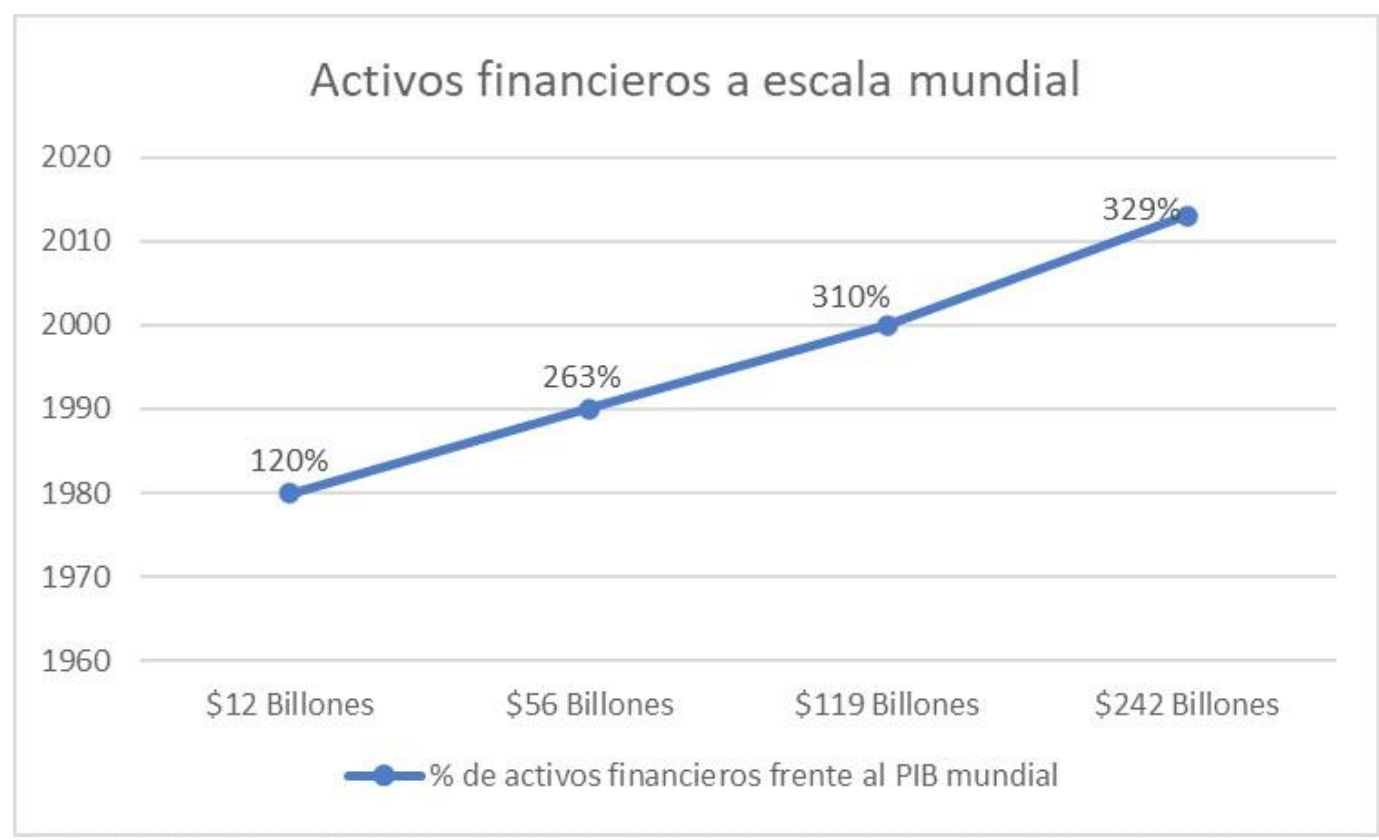

Fuente: Elaboración propia con información del informe Estado del Poder 2019 del Transnational Institute, TNI.

El poder de la ciudadanía queda velado, siendo el verdadero motor y soporte del crecimiento mundial, personalidades en los Estados Unidos como Ocasio-Cortéz nos hablan de un nuevo pacto global o "Green New Deal" (Pettifor, 2019: 1). Sin embargo, se debe llevar a cabo una transformación no solo estructural sino informativa a nivel global, dado que, hasta el día de hoy, el lenguaje técnico financiero es denso y complejo 
para la gran mayoría de las personas que son las más afectadas por cada decisión de endeudamiento en sus gobiernos.

La razón de nuestra impotencia política reside en la nebulosa y el misterio que rodean la creación del dinero y el funcionamiento del sistema monetario, hay muchísima incomprensión y confusión, siendo que el dinero no es más que una promesa de pago, cuando esta promesa se quiebra por la inestabilidad del mercado y la especulación, el valor se cae, recordemos que el dinero es una construcción social basada en la confianza y sostenida por ley. Cuando la confianza se desestabiliza a nivel de mercados este valor se ve comprometido provocando crisis, esto es lo que ha venido sucediendo en los últimos años en los Estados Unidos en donde el sistema financiero y económico capitalista a estado constantemente en crisis en cuanto a sus sistema económico y expansión;

La velocidad de expansión de la economía estadounidense del siglo XIX creaba grandes oportunidades para la especulación junto con la ausencia de instituciones adecuadas que regularan el mercado financiero y actuaran como prestamistas, estas carencias favorecían la aparición periódica de crisis (Pineda, 2011).

Siendo de tal manera que durante el siglo XIX y el XX, sucedieron alrededor de " 6 pánicos bancarios" (Pineda, 2011: 130), a nivel global entre los que se destacan los de 1837, 1857, 1873, 1893, 1907, y el Crac de 1929, sin dejar de mencionar que desde la era Margaret Thatcher se han sucedido otras "12 grandes crisis financieras, siendo la más reciente la del 2007-2008” (Bello, 2019: 59), esto significaría que las finanzas o el sector financiero son el motor central que impulsa las economías de las naciones hoy, siendo además una de sus características distintivas la financiación de las crisis.

Una nación puede ser tan rica o tan pobre como su sistema financiero y la fortaleza de sus instituciones se lo permita (entendiendo que esta permisibilidad está condicionada muchas veces); véase el ejemplo de países en África, América Latina o Asia, ante la carencia de autonomía monetaria proporcionada por instituciones sólidas, incluido un buen sistema de recaudación tributaria hace que los ciudadanos en estos países estén prácticamente indefensos y expuestos ante “entidades depredadoras" (Quijano, 2014) y crediticias extranjeras que explica esa dependencia de las regiones subdesarrolladas hacia los países centralistas o hegemónicos.

El asunto de las crisis y parafraseando a Stiglitz (2002), en un mundo hiperconectado e hiperglobalizado en donde las transacciones, el intercambio monetario, el aumento o desplome de mercados están a un click se hace necesario la "previsibilidad". Sin embargo, estamos hablando de mercados demasiados volátiles en donde no se produce ningún tipo de bien, la especulación y la confianza es prácticamente un "activo" que se hace imposible de controlar especialmente si mencionamos las transacciones bancarias y financieras que se hacen en las "sombras" las cuales no gozan de ninguna regulación.

El poder financiero tiene ese poder de fusionarse con el Estado, donde desaparece y reaparece un replanteamiento entre la división ideológica de la esfera pública y privada; entre los planos políticos y económicos; o entre el Estado y el mercado siendo este en última instancia una simbiosis en un modelo de mercado global hipercapitalizado de 
forma tal que "el poderoso capitolio de nuestra época el capital global financiarizado e hipermóvil es el Estado" (Hendrikse y Fernández, 2019: 26).

Esto lo podemos ver en la última crisis capitalista global, en donde el Estado entro a rescatar bancos y entidades financieras con el dinero de los contribuyentes, al igual que embargaban bonos soberanos en calidad de documentos negociables, mediante bonos y solicitudes de préstamo a la Reserva Federal, FED, así como se subían los techos de pagos de las mismas entidades financieras que provocaron la crisis económica global.

Debemos ver como el capital global en momentos críticos busca salidas no tan privadas colectivizando las pérdidas de un grupo minoritario con fondos públicos, por ejemplo,

Para finales del 2008 el presidente de Estados Unidos, George W. Bush, promulgo la Ley de Estabilización Económica de Emergencia mediante la cual se canalizarían 700.000 millones de dólares al mercado financiero. Esta medida buscaba ayudar tanto a los bancos fuertes para que continuaran ofreciendo préstamos nuevamente, como a aquellas instituciones bancarias que presentan dificultades, con el fin de que lograran estabilizarse. Los bancos que se beneficiaron serían; Citigroup, Goldman Sachs, Morgan Stanley, Wells Fargo, JPMorgan Chase, Bank of America, Merrill Lynch, State Street, Bank of New York Mellon Corp. El secretario del Tesoro de Estados Unidos en ese entonces, Henry Paulson, alegaba que usarían el dinero para comprar muchas de las deudas hipotecarias incobrables, todo esto con la salvedad que era dinero público y no privado el que circulaba al rescate del capital financiero. (Pineda, 2011:170).

Igual receta hicieron muchos otros países en el mundo en donde invirtieron ingente cantidad de dinero público, ya fuera mediante la emisión de bonos o el uso de los fondos soberanos para comprar-repagar deuda y nuevamente circular en el mercado financiero. A todo esto, sin dejar de mencionar los riesgos que conlleva y las cargas impositivas que a la larga traen en cada país que no puedan continuar solventando las deudas contraídas.

Las dimensiones y riesgos de la financiarización son varios, pero me concentrare en solo dos; debemos tener en cuenta en primer lugar, que la financiarización implica una creación ampliada de un tipo de endeudamiento en la población para sustituir los ingresos estancados con el fin de crear demanda de bienes y servicios, en segundo lugar; implica las llamadas innovaciones en ingeniería financiera que facilitarían la liquidez, siendo uno de los más importantes, y en última instancia el más perjudicial, puesto que fue la titulación, la cual consiste en hacer que los contratos tradicionalmente inmóviles como las hipotecas fueran líquidos o móviles y negociables como las hipotecas titularizadas que podrían negociarse lo que llevaría a la desaparición de la originaria relación acreedordeudor dando entrada a nuevas maneras de hacer dinero en el mercado de la especulación financiera.

\section{FINANCIARIZACIÓN Y COLONIALIDAD DEL PODER.}

La Colonialidad del Poder, conceptualización desarrollada por Quijano durante un proceso diverso en elementos analíticos, recoge la búsqueda de desestructurar un andamiaje establecido por la dominación y el control, se presenta como opción para 
relacionar y entender los nuevos modelos de control y dominio que se establecen en el siglo XXI.

Tenemos en cuenta que, Quijano no trabajó directamente en sus inicios la relación del poder capital/financiarización sobre la economía global y sus impactos en la hegemonía/ dominación capitalista, sino en una tercera etapa, que podemos identificar en un párrafo de Ríos, que hace alusión:

el primero de ellos radica entre los debates de la teoría de la dependencia de los años 60 y 70, donde se fueron forjando grandes intelectuales latinoamericanos, en el segundo tenemos a un Quijano más interesado por cubrir de manera especial las preocupaciones sobre la modernidad, Identidad, Estado y democracia. En un tercer estadio tenemos un Quijano más centrado en el análisis de la colonialidad del poder, el destino de la nación y la crisis sistémica del capitalismo global (Ríos, 2011: 311).

La financiarización toma mayor auge a partir de la década de los 90 con las crisis en América Latina, pero ya venía desarrollándose en el mundo con la expansión de la digitalidad y las transferencias del capital globalmente. Este nuevo modelo de hegemonía del "fascismo financiero" (Ríos, 2011: 391) surge como una forma de dependencia que imposibilita el proceso de una destrucción de la colonialidad, eso que Quijano consideraba necesaria para la liberación "la des/colonialidad del poder" (Ríos, 2011:210).

La construcción y elaboración teórico-conceptual del espacio geográfico entendido como localización simbólica más que una categoría física, menciona que se puede estar en el sur global como en el norte global, pero mientras la colonialidad exista no importa tanto en qué posición se desarrolle el pensamiento, esta permanecerá.

la colonialidad es uno de los elementos constitutivos y específicos del patrón mundial del poder capitalista, se funda en la imposición de una clasificación racial/étnica de la población del mundo como piedra angular de dicho patrón de poder y opera en cada uno de los planos, ámbitos, dimensiones materiales y subjetivas de la existencia social cotidiana y a escala societal (Quijano, 2000: 42).

De esta manera Aníbal Quijano definía no únicamente la colonialidad como una expresión de dominio y control colonial racial étnico sino también como una articulación de ese dominio, al control de "otros espacios" esos otros espacios "como ámbitos y dimensiones, materiales y subjetivas" (Quijano, 2000: 342). Es aquí donde la novedad de estas reflexiones entraría a jugar un rol protagónico, hoy sabemos que la dominación/ control hegemónico no es únicamente una categoría para describir una situación colonial ni de dominación en la modernidad, sino que entran en el rol los demás elementos que de por si van concéntricos a la modernidad desde la económica hasta las finanzas globales que nos atañe.

Quijano en su elaboración geográfica cultural y simbólica expresa el resurgimiento de una marginalidad y el sentimiento de inferioridad en las naciones colonizadas a partir de una dependencia colonial que tomaría nuevamente vigor con el análisis y discusión de las dependencias latinoamericanas en los últimos 50 años, pero también se vería reforzada por otras visiones globalistas que tendrían un fuerte empuje en el sector económico como la financiarización, Quijano identifica la cercanía de la colonialidad y su relación con el 
proceso de dominación económico, social, cultural y financiero actual como un proceso inacabado y que se extiende a lo largo y a lo ancho y que se verá especialmente reforzadas en las economías del sur global, siendo especialmente las naciones más endeudas y con bolsones de pobreza y dependencia, las intervenidas.

La clasificación fenotípica iniciada en Latinoamérica también fueron usadas en otras latitudes, siendo estas definidas como expresión externa de las diferencias raciales, el color de la piel fue definido como la "marca racial" (Quijano, 2000: 374), existía una clara diferenciación en otrora y hoy, frente al hecho que la racialidad se constituyera como elemento de control y poder, entre los que controlaban y dominaban el poder hegemónico y los que eran controlados por los detentores de este poder hegemónico.

Otros elementos que definían el pensamiento de Quijano, está directamente vinculado con la particularidad de la articulación colonial en la geopolítica global de los territorios y las organizaciones. Es de esta manera que la articulación de la geopolítica y la distribución de las razas en los lugares dominados jugo un papel en el cual eran sometidos como agentes tributarios, es decir y en palabra de Quijano se convertían en intermediarios en la cadena de transferencia de valor y de riquezas de la "periferia colonial" (Quijano, 2000: 375).

La colonialidad y dominio a través de la dependencia financiera o lo que el llamaría la "financierización estructural del capitalismo" (Ríos, 2010: 72), era una de las preocupaciones de Quijano que posteriormente contribuirían para entender las relaciones de poder y la colonialidad en el contexto global y latinoamericano del capitalismo más moderno. Quijano había desarrollado un núcleo de reflexiones constantes sobre el desarrollo de una criticidad no solo al modelo de desarrollo de los años 60 y 70 de la teoría de la dependencia, sino también a los intentos de elaborar una teoría emancipadora y liberadora desde Latinoamérica, esto implicaría no solo desde un plano subjetivo sino también desde lo material siendo en sus inicios reorientando desde la teórica clásica y la macro sociología, pasando por el desarrollo de la crítica del discurso socio antropológico funcionalista, y del estructuralismo, para pasar al debate del capitalismo mundial y los conceptos de la dependencia.

Parafraseando a Ríos (2011), el capitalismo neoliberal opera como una entidad de autodestrucción creadora de lo tradicional para imponer la modernidad esa modernidad capitalista que viene a sustituir valores simbólicos y culturales, la modernidad racionalidad capitalista que genera no solo modelos de conflictos socioeconómicos que son puntualmente coordinados por el sistema político administrativo del poder y capital financiero, sino que además acrecienta las brechas de pobreza y desigualdad en el sur global, en las regiones que históricamente han sido los escenarios de encuentros y desencuentros del capital y la extracción de materias primas para el mercado global.

El sistema mundo financiarizado como un elemento de facto se encontraba en procesos de reordenamiento global después de los 90, donde tomaría más fortaleza a nivel hegemónico como lo conocemos hoy en día, el modelo capital transnacional y el mercado financiero internacional estarían imponiendo medidas y coordinando dinámicas de “extracción y saqueo similar a la minería” (Sassen, 2019: 42). 
El análisis de Quijano actualmente es visto como un instrumento para una des/ colonización del pensamiento en un sistema donde la hegemonía se ha visto revitalizada en las últimas décadas contribuyendo a que el capital dominante del sistema-mundo se establezcan con nuevas directrices en los polos periféricos de la centralidad. Sin embargo, y pensando desde una epistemología del sur, desde una deconstrucción del sujeto/ ser pensante que busca una emancipación y liberación, podemos identificar riquezas analíticas y cognitivas en el pensamiento de Quijano o como mencionaría Boaventura De Sousa Santos en clave epistemológica "debemos descolonizar no solo el pensamiento del colonizado sino el conocimiento del colonizador” (Sousa Santos, 2018:187).

Ahora bien, todo este proceso de descolonización implica volcarnos a entender lo propio, pero también a decodificar el lenguaje del colonizador en este sentido, el lenguaje se volcó numérico y escala en los planos más elevados de la economía de los países más industrializados, siendo un lenguaje reservado en su gran mayoría para legos, en especial hombres "blancos" "con un nivel educativo "alto" y con un poder adquisitivo "medio y alto" de países ricos con políticas flexibles para sus propios países, pero rígidas para los países del sur global en donde obtienen la mayor parte de su ganancias en el cobro de deudas y embargos a naciones e instituciones públicas, con todo lo que representan estas acciones financieras para las naciones del sur global y su población.

\section{PALABRAS FINALES}

La vigencia del pensamiento de Aníbal Quijano es múltiple, hoy por hoy se hace cada vez más importante entender las relaciones de colonialidad y sus mutaciones, dado el proceso de transformaciones en el cual nos encontramos. Repensar desde y para América Latina en medio de una de las mayores crisis civilizatorias de nuestra historia, nos acerca a reflexionar el proceso de la colonialidad y el "sentipensar" que menciona (Escobar, 2014).

¿Cómo pensar el racismo, el etnocentrismo, la discriminación y las migraciones, la desigualdad, la pobreza, el saqueo financiero y especulador, la violencia estructural, los feminicidios, la corrupción de los gobiernos sin pensarlo desde la colonialidad del poder? Considero que no es posible, Aníbal Quijano dejo cimentadas las estructuras teóricoconceptuales para interpretar y entender las problemáticas latinoamericanas, pero también del mundo colonizado y saqueado en África, Asía, Latinoamérica, en general el sur global. No se debe malinterpretar la colonialidad del poder como algo extinto y superado una vez alcanzada la realización completa del proyecto emancipador, puesto que la colonialidad como estructura de más de 500 años, se han enraizado profundamente en las mentes de los colonizados y del colonizador.

Aníbal Quijano, Frantz Fanon, Enzo Faletto, Enrique Dussel, Marco Gandásegui, entre otros pensadores caribeños y latinoamericanos han desarrollado toda una serie de instrumentos teórico-metodológicos que nos proporcionan la esencia para comprender el ser-sujeto colonizado y emprender esa des/construcción y des/colonización, hacia un sujeto emancipado, debemos tener en cuenta que la emancipación del sujeto/sociedad no pasa únicamente por el plano subjetivo-simbólico y cultural. Este ha de ser una emancipación también fáctica, de asumir una materialidad estructural en cuanto a las posiciones de poder y de dominación que siempre han sido espacios unificados por un 
sector de la sociedad. Los latifundistas en la colonia, los burgueses en el incipiente desarrollo industrializado en Argentina, Brasil o Chile, los empresarios, banqueros y financistas en la actualidad hegemónica de la financiarización estructural del capital global.

Pensar Aníbal Quijano hoy, es pensar en las transformaciones venideras, en los movimientos sociales que hacen falta por venir y los que ya están en desarrollo, en la articulación de los instrumentos de organización sindical, gremial, ambiental, feministas, juventudes y organizaciones políticas para incidir en la cuestión del poder estatal. Además de pensar América Latina, Latinoamérica; desde Mesoamérica, el Caribe, la Amazonia, Abya Yala, los Andes, el Gran Chaco, el Cono Sur. Desde todas y cada uno de los espacios no solo geográfico culturales sino también enticos y simbólicos que se manifiestan en la esencia y la cultura de los sujetos.

Los panoramas actuales que conducen y ordenan la actual perspectiva sobre América Latina de acuerdo con Quijano estarían en la continuada y creciente polarización social de la población, las estadísticas de desempleo, la distribución de ingresos, la desproporción de los niveles de pobreza cada vez más elevados, ahora más que antes con la pandemia del covid19 estos niveles se verán incrementados.

La reprivatización social del Estado en donde se reduce de forma continua los gastos fiscales en servicios de educación, seguridad social, salud, infraestructura urbana y transporte, privatiza en más de los casos remata los recursos de producción bajo control estatal, las empresas estatales destinadas a la producción de mercaderías de exportación y a la producción de servicios público. Hacen que el circuito de la pobreza se incremente y las medidas populistas surjan como una alternativa de control y dominio social por parte de los intereses financieros transnacionales y locales.

\section{REFERENCIAS BIBLIOGRÁFICAS}

Bello, W., (2019). Finanzas Globales, en Informe Estado del Poder 2019, TNI. pp.58-67

Dutta, S., Thomson F. (2018). Financierización: guía básica, Ámsterdam, TNI, FUHEM Ecosocial, Attac. p. 50

Escobar, A. (2014). Sentipensar con la tierra: nuevas lecturas sobre desarrollo, territorio y diferencia, Medellín, Colombia, UNAULA, CLACSO.

Medialdea, G., Sanabria, A., (2013). La financiarización de la economía mundial: Hacia una caracterización, en Revista de Economía Mundial, núm. 33, Huelva, España, pp. 195-227

Hendrikse, R., Fernández, R. (2019). OffShore Finance, en Informe Estado del Poder 2019, TNI, pp. 24-35

Pettifor, A. (2019). El poder latente de la ciudadanía y la creación del aval público en

Informe Estado del Poder 2019, TNI. pp. 1-13

Pineda, L. (2011). La Crisis Financiera de los Estados Unidos y la respuesta regulatoria internacional en Revista Aequitas, vol. 1, pp. 129-214. 
Quijano, A. (2000). Colonialidad del poder y clasificación social, en Journal of World Systems Research, vi, 2, Summer/Fall, Special Issue Festschrift. Special Issue: Festchrift for Immanuel Wallerstein-Part I

Quijano, A. (2000). Colonialidad del poder, eurocentrismo y América Latina en libro: La colonialidad del saber: eurocentrismo y ciencia sociales. Perspectivas Latinoamericanas. Compilador, Edgardo Lander, CLACSO, Buenos Aires, p. 246.

Quijano, A. (2014). Colonialidad del poder y clasificación social, en Cuestiones y horizontes: de la dependencia histórica-estructural a la colonialidad/descolonialidad del poder, Buenos Aires, CLACSO.

Ríos, J. (2011). El quehacer sociológico en América Latina. Un diálogo teórico con sus actores. Lima, Perú, UNMSM.

Ríos, J. (2010). Crisis y Ciencias Sociales entrevista a Aníbal Quijano, Revista Tareas, núm. 136, pp. 67-94

Sassen, S. (2019). Altas Finanzas, Un sector extractivo, entrevista en: Informe Estado del Poder 2019, TNI. pp. 37-43

Sousa Santos, B. (2018). O fim do Imperio Cognitivo, Coimbra, Almedina. p. 521

Stiglitz, J. (2002). El malestar de la globalización, Madrid, España, editorial Taurus. p.

Escudero Núñez, C. (2021). La financiarización estructural del capitalismo, una aproximación a Aníbal Quijano. Puriq, 3(4), 503-514. https://doi.org/10.37073/puriq.3.4.218 